Gibbon, J. H., Jun. (1937). Arch. Surg., Chicago, 34, 1105.

(1939). Surg. Gynec. Obstet., 69, 602.

elmsworth, J. A.. Clark, L. C., jun., Kaplan, S., Sherman, R. T., and Lareen, T. (1952a). J. thorac. Surg., 24, 117

- $-\frac{}{\mathrm{J}}$ (1952b). J. Amer. med. Ass., 150, 451

ongbloed, J. (1949). Surg. Gynec. Obstet., 89, 684.

(1950). Ned. T. Geneesk., 94, 161

(1951). S. Afr. med. J., 25, 840 .

antrowitz, A., Hurwitt, E., and Kantrowitz, A. (1951). Arch. Surg., Chicago, 63, 604.

and Kantrowitz, A. (1950). Froc. Soc. exp. Biol., N.Y., 74, 193 arlson, K. E., Dennis, C., Westover, D., and Sanderson, D. (1951). Surgery, $29,678$.

Kolff, W. J. (1946). The Artificial Kidney. Kok, Kampen, Holland.

and Dubbelman, C. P. (1949). Geneesk. Gids., 27, 241.

Lorincz, A. L., Jacoby, J. J., and Livingstone, H. M. (1948). Anesthestology, 9. 162 .

Miller, B. J., Gibbon, J. H., jun., and Gibbon, M. H. (1951). Ann. Surg., 134, 694

Mustard, W. T., and Chute, A. L. (1951). Surgery, 30, 684

Peirce, E. C., and Southworth, J. L. (1953). Arch. Surg., Chicago, 66, 218 Potts, W. J., Riker, W. L., DeBord, R., and Andrews, C. E. (1952) Surgery, 31, 161 .

Rossi, R. (1950). Minerva med., Torina, 41, 835.

Sewell, W. H., jun., and Glenn, W. W. L. (1950). Surgery, 28, 474

Southworth, J. L., Peirce, E. C., Tyson, T., and Bowman, R. L. (1953) Arch. Surg. Chicago, 66, 53.

Stokes, T. L., and Flick, J. B., jun. (1950). Proc. Soc. exp. Biol., N.Y., 73 528.

and Gibbon, J. H., jun. (1950). Surg. Gynec. Obstet., 91, 138.

Thomas, J. A., and Beaudouin, P. (1951). J. Physiol., Parts, 43, 311

Tosatti, E. (1949). G. Ital. Anest., 15, 120.

Wesolowski, S. A., Miller, H. H., Halkett, J. A. E., and Welch, C. S. (1950). Bull. N New Engl. med.' Cent., 12, 41 .

EXPERIMENTAL PHYSIOLOGY OF A HEART-LUNG MACHINE IN PARALLEL WITH NORMAL CIRCULATION*

BY

D. G. MELROSE, B.M., B.Ch.

J. W. BASSETT, M.D.

P. BEACONSFIELD, M.D.

I. G. GRABER, M.D., F.R.C.S.Ed.

AND

RALPH SHACKMAN, M.B., F.R.C.S.

(From the Department of Surgery, Postgraduate Medical School of London

Recognizing the magnitude of the task involved in the mechanical maintenance of the entire circulation in humans, we turned our attention to the lesser problem of assisting the natural circulation by shunting part of it from vein to artery through the heart-lung machine. To assess the value of the heart-lung machine in resuscitation and in the treatment of a failing circulation, and to acquire information to be applied later to the problem of complete artificial maintenance of the circulation in man, a series of experiments was carried out in dogs.

In the planning and execution of these experiments we were helped by experience gained from a large number of studies carried out with earlier machines. These studies included the perfusion of isolated organs, which proved particularly valuable in providing the basis of the present technique, and enabled controlled conditions to be established.

\section{The Experiments}

Thirty greyhound dogs, each weighing between 20 and $30 \mathrm{~kg}$. and apparently healthy, were used. They were dewormed and given intramuscular penicillin $(300,000$ units 8-hourly) for two days prior to the day of an experiment, when each dog was anaesthetized with intra-

*This work was carried out at the Buckston Browne Research Farm, Kent, by permission of the President and Council of the Royal College of Surgeons of England. peritoneal pentobarbitone sodium (30 mg. per $\mathrm{kg}$. body weight). A cuffed tube was introduced into the trachea and inflated, and was then connected to a Benedict-Roth spirometer containing oxygen. Electrocardiograph leads were fixed to the two fore-limbs and to the right hindlimb.

A small incision was made in the neck, and an external jugular vein and a carotid artery were exposed. A radioopaque catheter was then introduced into each of these vessels and was guided under fluoroscopic control into the right auricle and the ascending aorta or left ventricle respectively. The catheters were connected to continuously recording manometers and arranged so that blood samples could be obtained from them. The patency of each was maintained by flushing with saline which contained heparin $(2 \mathrm{mg}$. per $100 \mathrm{ml}$.).

One or other deep femoral artery was exposed together with one of the major branches of a femoral vein. A tapered plastic catheter was then introduced into the deep femoral artery and connected to the "arterial" tube of the heart-lung machine. A plastic catheter 25 $\mathrm{cm}$. in length, with numerous side openings, was passed into the femoral vein and advanced until its tip was judged to rest within the thoracic portion of the inferior vena cava. Connexion was made between this catheter and the "venous" tube of the heart-lung machine.

Concurrently with the preparation of the animal the machine was being assembled and made ready for perfusion (see Appendix I). In the first five experiments it was charged with approximately $\mathbf{7 5 0}$ ml. of donor dog's blood, but subsequently, because facilities for sterile blood collection proved inadequate and no definitive method could be achieved for cross-matching mongrel and greyhound blood, a solution of $6 \%$ dextran in normal saline was used.

The animals were now given heparin or dextran sulphate (Walton, 1951), 1-2 mg. per kg. being used. Primary readings were then made of the arterial and central venous pressures, th e oxygen consumption, and the electrocardiog ra $\mathrm{ph}$, which were then recorded con-
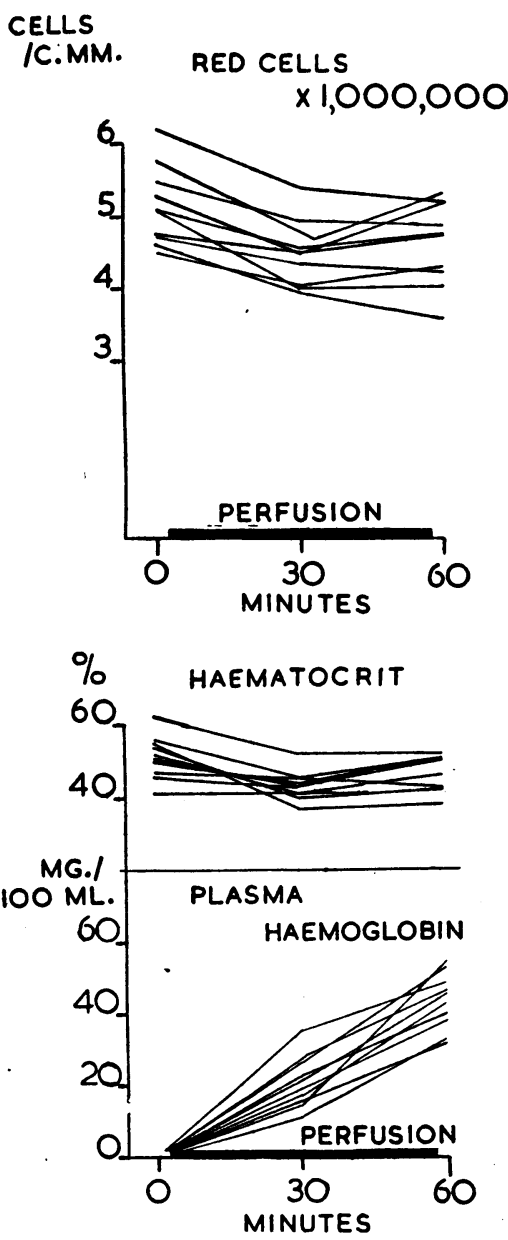

FIG. 1.-Red-cell count, haematocrit, and plasma haemoglobin in 10 dogs before, during, and immediately after one hour's perfusion. 


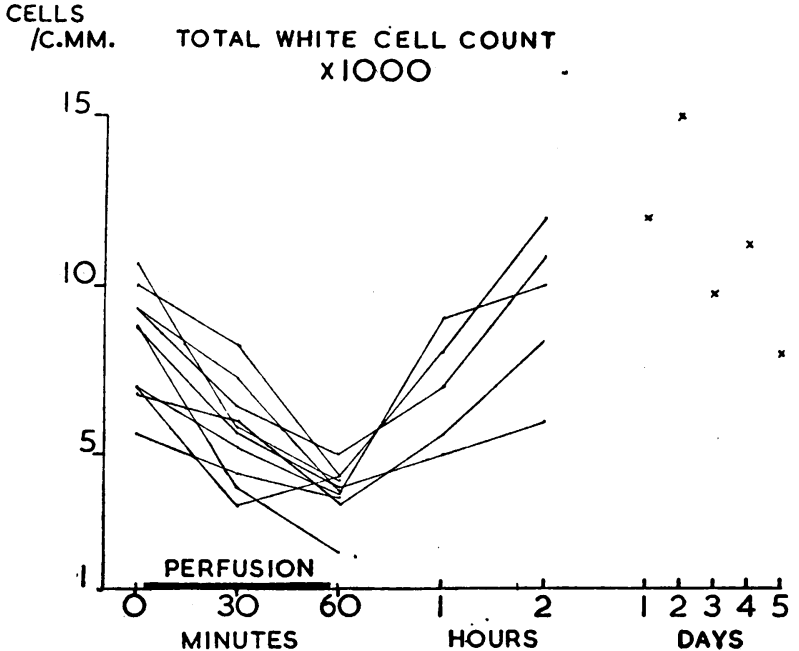

FIG. 2.-White-cell count in 10 dogs before, during, and for five days after one hour's perfusion.

tinuously. Arterial and venous blood samples were also obtained. On these samples were made the following determinations, using standard techniques (Appendix II) : (1) arterial and venous blood oxygen content; (2) counts of red cells, platelets, and leucocytes, including the differential and Arneth counts ; (3) haematocrit and plasma haemoglobin ; (4) plasma sodium, potassium, and chloride, sugar, urea, and carbon-dioxide combining power ; and (5) $\mathrm{pH}$.

The heart-lung machine was now started and adjusted to circulate at $50-100 \mathrm{ml}$. a minute, and then increased in rate gradually to between 750 and $1,000 \mathrm{ml}$. a minute. In most experiments the perfusion was continued for a standard time of one hour, blood samples being taken at intervals during this time and again ten minutes after

RATIO OF GROUP I GRANULOCYTES GROUP IV GRANULOCYTES measuremen ts

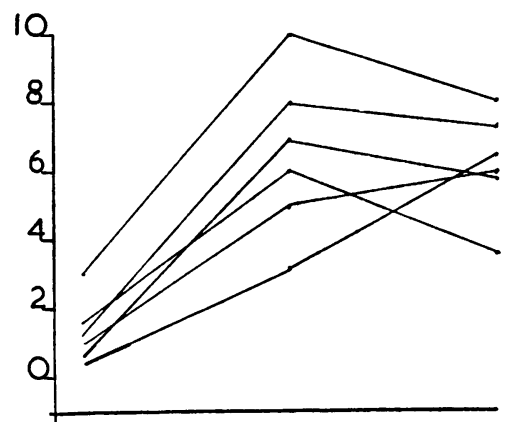
had been made the cannulae we re removed, the carotid artery and external jugular vein ligated, and the femoral artery and the vein repaired or ligated. Prot amine sulphate was given to neutralize the heparin effect and the dog was allowed to recover conscious ness. Subcutaneous vein blood samples were subsequently taken hourly for two hours and then daily for five days, and on these samples a full leucocy te count was carried out. FiG. 3.- Ratio of Group I to Group IV lymphocytes to granulocytes in 10 dogs before, during, and for two hours after perfusion.
The results of the experiments are considered under four headings : (1) clinical assessment of the effect of the procedure and analysis of morbidity and mortality; (2) the changes in the blood itself while circulating through the machine ; $(3)$ the general circulatory effects produced by the artificial circulation ; and (4) evidence of the efficiency of the machine as an extrapulmonary oxygenator.

\section{Clinical Assessment of the Procedure}

No death directly attributable to the extracorporeal circulation occurred in the 30 dogs studied. Four dogs did not survive the procedure. Two died on the operating table as a result of misjudgments, one from an uncontrollable haemorrhage, and another from a period of asphyxia purposely induced to initiate anoxic collapse of the circulation. One died after prolonged hypotension which began immediately after the perfusion had started and which was probably the effect of donor blood, and one died of peritonitis following intraperitoneal pentobarbitone sodium anaesthesia.

Assessment of recovery from the procedure was complicated by the fact that in 18 cases the femoral artery was ligated and the leg in question temporarily immobilized. A greyhound is reluctant to get to its feet in these circumstances, but clinically measurable dysfunction was absent in all of the 26 animals which survived. After two to three days the dogs were normally active. When arterial repair was successful (six cases) and when the blood had returned into the superior vena cava (two cases) activity became normal within 12 hours. Twenty-five dogs were observed for periods up to three months, and were sacrificed in good condition. Post-mortem examinations did not reveal any abnormalities. One animal preserved as a pet is in such good condition that he has recently sired progeny destined for competitive coursing.

\section{Effect of the Machine on the Blood}

The most notable effect of the machine on blood circulating through it was on the cellular elements. After one hour's perfusion in 10 dogs the average redcell count fell from $5,150,000$ to $4,500,000$ per c.mm., the average haematocrit fell from 51 to $46 \%$, and the average plasma haemoglobin concentration rose to $43 \mathrm{mg}$. per 100 ml. (Fig. 1).

A dramatic fall oc-
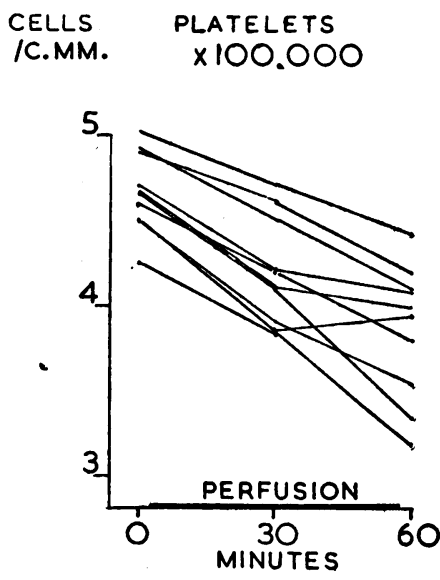

FIG. 4.-Platelet count in 10 dogs before, during, and immediately after perfusion.

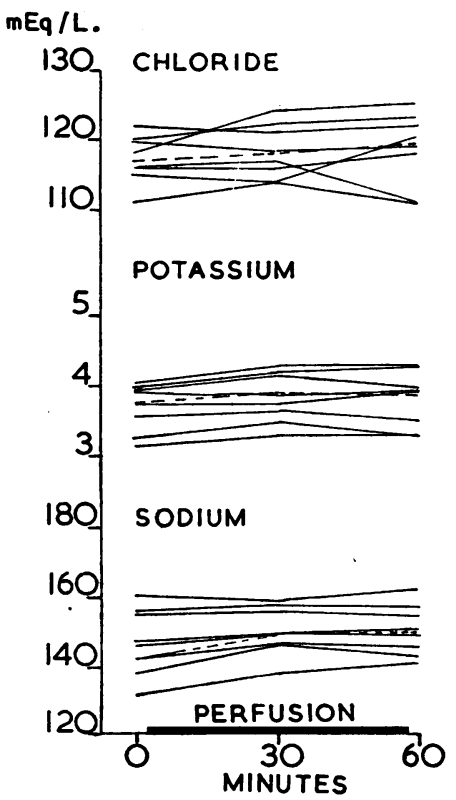

FIG. 5.-Plasma chloride, plasma potassium, and plasma sodium in 10 dogs, 'before, during, and immediately after perfusion. 
cells during the same time (Fig. 2)-from an average primary value of 8,200 per c.mm. to an average value of 4,800 . The greatest fall recorded was from 8,800 to 2,100 per c.mm. One hour after cessation of perfusion the average value had risen again to 6,000 , and one hour later it had become 8,800 per c.mm. A leucocytosis persisted for five days in all animals.

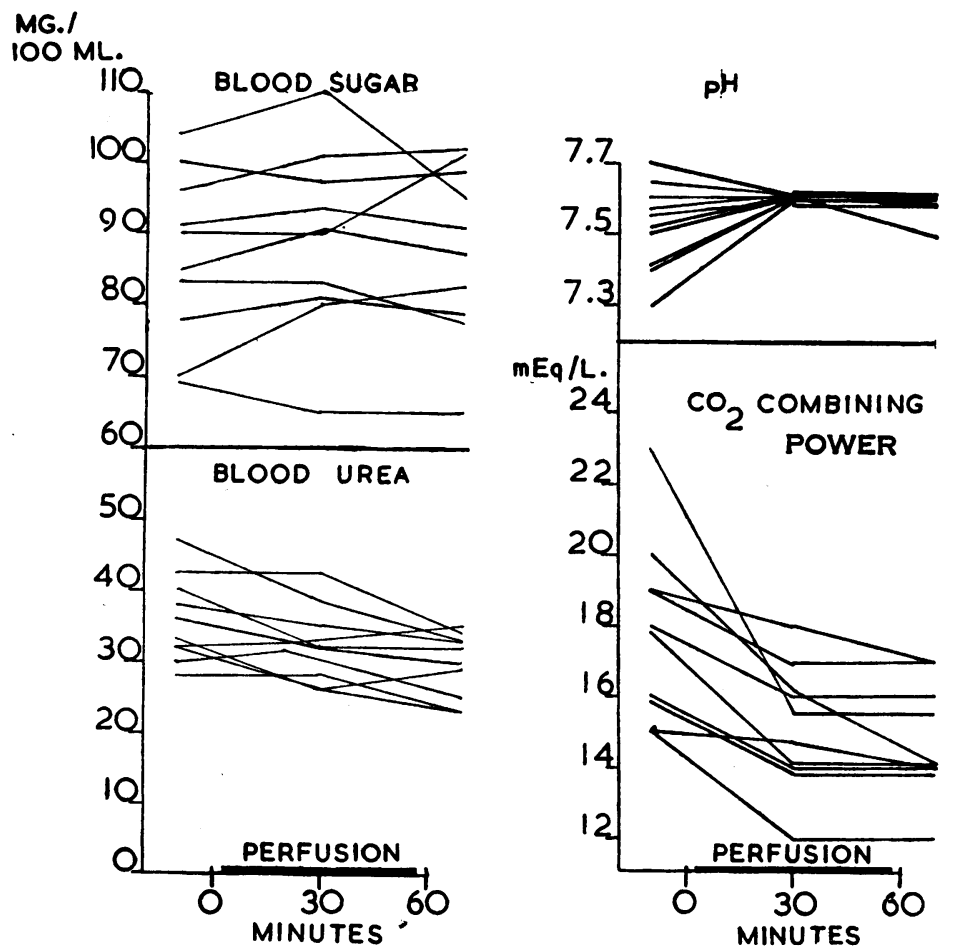

FIG. 6.-Blood sugar, blood urea, $p H$, and plasma carbon-dioxide combining power in 10 dogs before, during, and immediately after perfusion.

The differential count, expressed as the ratio of lymphocytes to granulocytes, and the Arneth count, expressed as the ratio of Group I granulocytes to those of Group IV granulocytes (Fig. 3), showed, after 60 'minutes' perfusion, a rise in the average lymphocyte:granulocyte ratio from 0.39 to 0.6 , and a marked rise from 1.3 to 7.8 in the average ratio of Group I granulocytes to Group IV granulocytes. This indicated that the fall in white cells particularly affected the granulocytes, and that the more elderly are more greatly affected than the less-developed ones. Two hours after perfusion the ratio of lymphocytes to granulocytes had fallen again to 0.36 , but the ratio of Group I to Group IV granulocytes had remained elevated at 6.2 .

The platelet count fell from an average value of 463,000 per c.mm. in one hour to an average value of 378,000 (Fig. 4).

In contrast to the cellular elements the plasma electrolytes were relatively unaffected. After one hour's perfusion the average plasma sodium had increased from 149 to $156 \mathrm{mEq}$ per litre, the average plasma chloride from 116 to $120 \mathrm{mEq}$ per litre, and the average plasma potassium from 3.6 to $4.0 \mathrm{mEq}$ per litre (Fig. 5). During the same time the average plasma carbon-dioxide combining power had fallen from 18.0 to $16.0 \mathrm{mEq}$ per litre, while the $p \mathrm{H}$ had risen from an average of 7.5 to an average of 7.6 (Fig. 6). No significant change was recorded in the measurements of blood sugar and blood urea, the former falling from an average value of 86 to $82 \mathrm{mg}$. per $100 \mathrm{ml}$. and the latter falling from an average value of 36 to $30 \mathrm{mg}$. per $100 \mathrm{ml}$. (Fig. 6).

Determinations of the plasma proteins were invalidated by the use of dextran.

\section{Effect of the Machine on the Circulation}

In the first five experiments, when donor blood was used, the initial delivery from the machine produced a fall in arterial blood pressure which persisted throughout the per- fusion. In the remainder, when a solution of dextran in sodium chloride was used, the introduction, maintenance, and termination of the perfusion was accomplished without untoward events, the blood pressure, pulse, and respiratory rates remaining virtually constant.

Electrocardiograph tracings revealed no changes other than an occasional alteration in cardiac rate. No arrhythmias were induced even when the perfusion was started or stopped suddenly.

The cardiac-output changes deduced by application of the Fick principle to the measurements of oxygen consumption and arteriovenous oxygen differences are well exemplified in the detailed consideration of Dog No. 20. This dog remained evenly narcotized throughout two and a half hours. Respiration was deep and regular, and before the beginning of the perfusion the oxygen consumption was $140 \mathrm{c.cm}$. a minute, the cardiac output 3.2 litres a minute, the mean arterial pressure $115 \mathrm{~mm}$. $\mathrm{Hg}$, and the central venous pressure $+2 \mathrm{~cm}$. $\mathrm{H}_{2} \mathrm{O}$. Three minutes after perfusion at $750 \mathrm{ml}$. a minute the oxygen consumption had fallen to $115 \mathrm{c} . \mathrm{cm}$. a minute and the central venous pressure had fallen to $-1 \mathrm{~cm}$. $\mathrm{H}_{2} \mathrm{O}$. The mean arterial pressure had not altered. After 30 minutes the oxygen consumption had fallen to $85 \mathrm{c.cm}$. a minute and the cardiac output to 2 litres a minute. The mean arterial pressure was then $118 \mathrm{~mm}$. $\mathrm{Hg}$ and the central venous pressure $+1 \mathrm{~cm}$. $\mathrm{H}_{2} \mathrm{O}$. Just after perfusion stopped the oxygen consumption rose to $160 \mathrm{c.cm}$. a minute for four minutes and then fell to $95 \mathrm{c} . \mathrm{cm}$. a minute during the succeeding five minutes. At this time the cardiac output was 2.3 litres a minute, the mean arterial pressure $115 \mathrm{~mm}$. $\mathrm{Hg}$, and the central venous pressure $+2 \mathrm{~cm}$. $\mathrm{H}_{2} \mathrm{O}$.

Similar determinations of cardiac output were carried out in 12 dogs (Fig. 7). In nine the cardiac output fell during perfusion, in one it remained unaltered, and in two it rose. In seven of the nine dogs in which the cardiac output fell the extent of the fall approximated the rate of perfusion, averaging $850 \mathrm{ml}$. a minute.

\section{Evidence of Efficiency of the Machine as an Extrapulmonary Oxygenator}

Oxygen can undoubtedly be introduced into a recipient's blood stream by means of the heart-lung machine. In a single dog, for example, there was an oxygen difference of 15 vols.\% between the venous blood entering the machine and the arterialized blood leaving it. And, since the rate of blood-flow through the machine was 1 litre a minute, approximately $150 \mathrm{c.cm}$. of oxygen a minute was introduced.

In order to determine if benefit followed from the extrapulmonary addition of oxygen six dogs were made anoxic by reducing the concentration of oxygen in the inspired air, replacing it with nitrogen. Venous blood, removed from the distal inferior vena cava, was returned after arterialization into the femoral artery in two dogs, into the thoracic aorta in two dogs, and into the superior vena cava in two dogs. The rate of perfusion did not exceed 1 litre a minute.

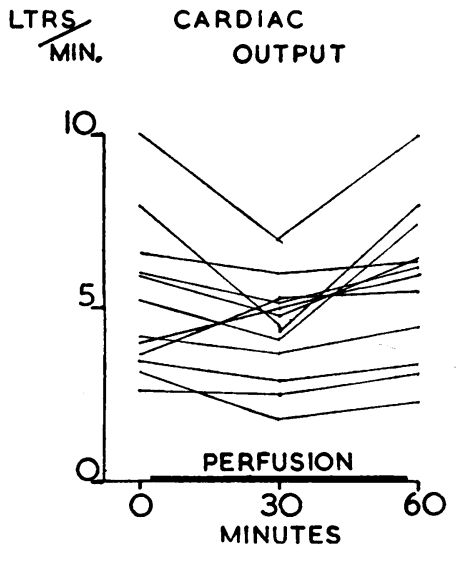

Fig. 7.-Cardiac output in 12 dogs before, during, and immediately after perfusion. 
In each case oxygen was introduced into the circulation, but striking differences were revealed in the three pairs of dogs (Fig. 8). In the first two dogs, when the perfusion was returned into the femoral artery, there was little apparent effect on the oxygen content of the carotid artery blood, and the cephalic end of the dogs remained anoxic. After the animals had been breathing pure nitrogen for ten minutes the oxygen content of this blood had fallen to $23 \%$. At the same time, however, the caudal end received an abundance of oxygen from the artificial lung, blood returning to the machine from the distal inferior vena cava being $65 \%$ saturated.

The perfusion was stopped at this point and complete anoxia maintained until cardiac arrhythmia and respiratory arrest had occurred. Resumption of the perfusion then restored respiration in both dogs and induced a normal heart-beart in one. The oxygen content of the carotid-artery blood was at this time identical with that of blood leaving the machine. In the second animal the heart ceased to beat after a short period of ventricular fibrillation, but perfusion was continued for two and a half hours, during which time natural respiration continued and the tongue and pupillary reflexes remained active.

In the second two dogs, in which the artificial circulation was returned into the aorta proximal to the splanchnic and renal arteries, a good perfusion of the cranial vessels was obtained, and the carotid-artery blood content did not fall below $50 \%$ even when pure nitrogen had been inspired for ten minutes.

In the last two dogs, in which arterialized blood was returned into the superior vena cava, the carotid-artery blood content was $52 \%$ ten minutes after exclusion of oxygen from the inspired air.

\section{Discussion}

The use of $6 \%$ dextran in sodium chloride to charge the heart-lung machine greatly contributes to its effective application to animal experimentation. The collection of blood from donor dogs, and its accurate cross-matching, is a difficult problem. In the five experiments in which donor blood was used, hypotension occurred when the contents of the machine were introduced into the circulation. We were not able to account for this, and it was concluded that an unknown factor in the donor's blood was responsible. The barbiturate used to anaesthetize the donor, the presence of products associated with exsanguination, bacterial contamination, and serological and cellular incompatibility were all possibly implicated.

No effects other than haemodilution and a resulting anaemia followed the use of dextran solution. The fall in the number of red cells is undoubtedly due to this deliberate haemodilution, for were the sole cause haemolysis the fall would not have exceeded $0.3 \%$, and would not have been measurable. Of course it may be argued that no account is taken in the calculation of the fact that haemolysed blood may be fixed in the tissues. However, even if a figure of $200 \mathrm{mg}$. per $100 \mathrm{ml}$. is taken as the level of haemolysis, a figure considerably larger than any found in in vitro experiments, the fall in the red-cell count would only be in the order of $1 \%$.

The amount of haemolysis is of no real consequence. No deleterious effects are to be expected from the liberation during perfusion of relatively minor quantities of haemoglobin. Much greater amounts have been administered to human beings without harm (O'Shaughnessy, Mansell, and Slome, 1939).
Deliberate haemodilution also accounts for much of the fall in the number of circulating platelets, which is too small to be of significance, but it cannot be responsible for the magnitude of the change in leucocyte values. Considerable destruction of circulating white cells does occur, and the resulting leucopenia may constitute a grave impediment to continuous perfusions over long periods. This problem is being studied at the present time, though it is evident
A

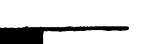

B
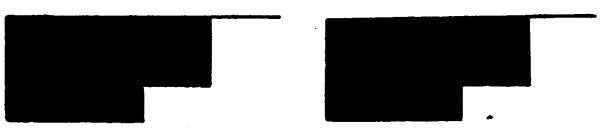<smiles>[I-]</smiles>

FIG. 8.-Percentage saturation of carotid artery blood in three dogs, A, B, and C, in which anoxia was induced by reduction of oxygen in the inspired air. Artithoracic aorta in $B$, and into the superior vena cava in $C$.

that perfusions of short duration, such as are reported, need not be rejected on account of their effect on the leucocytes.

The alterations in the electrolyte balance are of a very small order, and in the main are caused by the addition of unbalanced fluids to the circulation, and by the absence of an accurate means of adjustment of the carbon dioxide tension in the oxygenator. The first is easily rectified, the second awaits the development of a device capable of regulating the carbon dioxide tension from the $p H$ of the circulating blood. A device of this nature has been successfully exploited by Miller, Gibbon, and Gibbon (1951).

No untoward physiological effects accompany the shunting of a part of the natural circulation through the heartlung machine. Changes in arterial pressure, pulse, and respiration rate are slight, and animals appear clinically unaffected by the procedure. Cardiac output determinations seem to indicate that a fall occurs when the perfusion is running, though it would not be wise to claim too much from these results, which are not statistically significant. In carrying out these determinations much difficulty was encountered in establishing a satisfactory baseline, particularly when pentobarbitone sodium was used as an anaesthetic. The smallest variation in the depth of narcosis altered the cardiac output, and we rarely achieved a uniform depth throughout the procedure. Even though the doses of pentobarbitone sodium were adjusted according to the weights of the animals the dogs did not all react in the same fashion. In some the dose was more than enough and produced deep anaesthesia, while in others it did no more than produce light narcosis. Even when anaesthesia was produced by cyclopropane, administered by a skilled anaesthetist, three hours of carefully regulated anaesthesia was required before two consecutive cardiac outputs proved to be identical. 
Oxygen can be introduced into the blood stream by this method, and the extrapulmonary addition is of benefit to dogs made anoxic by a reduction of oxygen in the inspired air. The site of return of artificially arterialized blood is of great importance, and should be either into a central vein or into an artery close to the heart.

For these reasons it is felt that the heart-lung machine is now ready for clinical trials in selected cases of extreme cardio-respiratory dysfunction. In those patients in whom derangement of pulmonary function is the chief symptom, it may be advantageous to return the arterialized blood into a central vein, thus greatly simplifying the cannulation and making the surgical intervention a relatively minor one. Though no shunting of blood around the heart would occur in this technique, it is possible that the improved oxygenation would reduce the demands on the heart, and secondarily reduce its work.

Where the myocardium is primarily involved it is suggested that continuous venesection with return of arterialized blood into the arterial circulation will relieve the heart of part of its burden.

\section{APPENDIX I}

The oxygenator and connecting-blocks were chemically sterilized with " roccal" detergent and $3 \%$ formalin, being steeped in the solution for twelve hours. The tubing and cannulae, which we used only once, were autoclaved. After assembly the apparatus was washed with at least 40 litres of sterile distilled water to which had been added enough sodium chloride to provide approximate isotonicity. Frequent checks for the presence of formalin provided an indication of the efficiency of the washing process. When two checks were negative the wash-outs were discontinued and the apparatus was charged with donor blood or dextran solution. After circulation through the by-pass tube to ensure that no air bubbles remained in the arterial line, the machine was ready for use.

\section{APPENDIX II}

1. The arterial and venous blood oxygen were measured by the method of Van Slyke and Neill (1924).

2. The red-cell, platelet, leucocyte, differential, and Arneth counts were made, and haematocrit values found by standard methods (Dacie, 1950).

3. The plasma haemoglobin was estimated as oxyhaemoglobin on a Spekker absorptiometer modified to accept 1 by 6 in. $(2.5$ by $15 \mathrm{~cm}$.) test-tube cuvettes. A standard oxyhaemoglobin curve was prepared for each estimation in the following manner: 3-ml. aliquots of plasma were placed in each of five cuvettes; to the first was added $8 \mathrm{ml}$. of dilute ammonia reagent $\left(5 \mathrm{ml}\right.$. concentrated $\mathrm{NH}_{3}$ per litre), and this served as a plasma blank; to the remainder was added $0.02,0.04,0.06$, and $0.08 \mathrm{ml}$. of whole blood diluted 1 in 2 with normal saline; these were then diluted with $8 \mathrm{ml}$. of ammonia reagent and read against the plasma blank. $3 \mathrm{ml}$. of plasma obtained from samples taken during the experiment was -similarly treated and compared with the standard curve.

4. The plasma sodium and plasma potassium were determined by means of an internal standard flame photometer similar to that described by Berry, Chappell, and Barnes (1946).

5. The plasma chloride, plasma $\mathrm{CO}_{2}$ combining power, blood sugar, and blood urea were estimated by standard methods (King, 1951).

6. The $p \mathrm{H}$ was measured by a Muirhead $p \mathrm{H}$ meter type D-303-b.

We would like to express our gratitude to the President and Council of the Royal College of Surgeons of England for their kind permission to work at the Buckston Browne Research Farm, Downe, Kent, and to Sir Arthur Keith and Professor David Slome for their many kindnesses to us while working there. We are indebted to the directors of Messrs. A. C. Cossor Ltd. for their generosity in placing a direct-writing electrocardiograph at our disposal.

\section{RFFERENCES}

Berry, J. W., Chappeli, D. G., and Barnes, R. B. (1946). Industr. Engng Chem. (Ann. Ed.), 18, 19.

Dacie, J. V. (1950), Practical Haematology. Churchill, London.

King, E. J. (1951). Micro-analysis in Medical Biochemistry. Churchill, London.

Miller, B. J., Gibbon, J. H., jun., and Gibbon, M. H. (1951). Ann. Surg., 134, 694 .

O'Shaughnessy, L., Mansell, H. E., and Slome, D. (1939). Lancet, 2, 1068. Van Slyke, D. D., and Neill, J. M. (1924). J. biol. Chem., 61, 523.

Walton, K. (1951). Proc. roy. Soc. Med., 44, 563.

\section{POST-INOCULATION POLIOMYELITIS}

\author{
BY \\ JAMES GRANT, M.D., D.P.H. \\ Medical Officer of Health, Gateshead, and Medical \\ Superintendent, Sheriff Hill Hospital
}

The successful prophylaxis of diphtheria through the mass immunization of very young children with diphtheria toxoid was associated with - few mishaps of importance. When given subcutaneously, the alumprecipitated toxoid commonly gave rise to a painless nodule which was gradually absorbed, but occasionally there was an inflammatory swelling and very rarely a sterile abscess. These rare reactions to the toxoid were minimized by intramuscular administration, a route which was necessary for the injection of the pertussis vaccine introduced in 1946 and of combined diphtheria toxoid and pertussis vaccine made available in 1947 Since then the latter product has been increasingly used to immunize children simultaneously against diphtheria and whooping-cough by one series of injections.

In 1948 Martin (1950) observed flaccid paralysis of the arm in two children, each of whom had received an inoculation of a prophylactic in the paralysed limb within the preceding three weeks. Having traced and studied 15 other patients who had developed limb paralysis following injections of antigens in 1944-9, he concluded that all of these had really suffered from poliomyelitis. Gale (1950) was able to add 56 cases of limb paralysis following the inoculation of prophylactics, and then, independently and simultaneously, McCloskey (1950) and Geffen (1950) published their findings during two epidemics of poliomyelitis in 1949. In Melbourne, McCloskey found that 35 out of 340 patients with poliomyelitis had been inoculated against diphtheria or whooping-cough within three months before the onset of the illness, and that the paralysis affected the inoculated limb in 24 out of 31 patients about whom full information was obtained. Geffen reported that out of 182 poliomyelitis patients under 5 years of age in London, 37 had been recently inoculated and about 30 of these suffered from paralysis, affecting particularly the limb recently injected. Investigating a small group of the London children, MacCallum (1950) was able to isolate the poliomyelitis virus from the stools of two children with paralysis of a recently inoculated limb and from three other inoculated children suffering from poliomyelitis without paralysis. Hill and Knowelden (1950) carried out a statistical inquiry, covering 33 areas, into the incidence of paralysis as a sequel to recent inoculation in 1949, and concluded that this misfortune occurred more frequently within a period of one month after the inoculation than could be attributed to chance.

On the other hand, Culley (1951) could find only nine recently inoculated persons among the 380 Welsh 